\title{
IMPURITY MEASUREMENTS IN PLT
}

\author{
BY
}

H. F, DYLLA

\section{PLASMA PHYSICS LABORATORY}

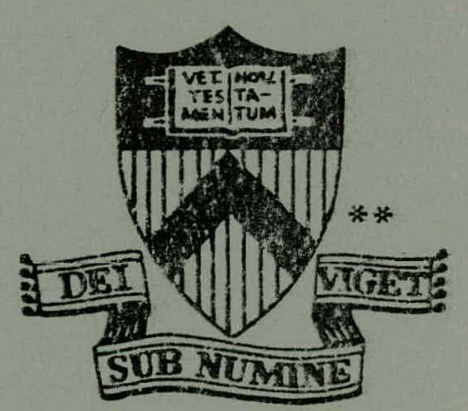

\section{PRINCETON \\ UNIVERSITY PRINCETON, NEW JERSEY}

Thj.s work was supportaä by U. S. Energy Research and Development Adrinistration Contract EY-?6-C-02-3073. Reproduction, translation, pitilication, use and disposal, in whole or in part, by or for the United stares Government i.s permitted. 


\section{DISCLAIMER}

This report was prepared as an account of work sponsored by an agency of the United States Government. Neither the United States Government nor any agency Thereof, nor any of their employees, makes any warranty, express or implied, or assumes any legal liability or responsibility for the accuracy, completeness, or usefulness of any information, apparatus, product, or process disclosed, or represents that its use would not infringe privately owned rights. Reference herein to any specific commercial product, process, or service by trade name, trademark, manufacturer, or otherwise does not necessarily constitute or imply its endorsement, recommendation, or favoring by the United States Government or any agency thereof. The views and opinions of authors expressed herein do not necessarily state or reflect those of the United States Government or any agency thereof. 


\section{DISCLAIMER}

Portions of this document may be illegible in electronic image products. Images are produced from the best available original document. 
NOTICE

This report was prepared as an account of work sponsored by the United states Govermment. Neither the United States nor the United States Energy Research and Development Administration, nor any of their employees, nor any of their contractors, subcontractors, or their employees, makes any warranty, express or implied, or assumes any legal liability or responsibility for the accuracy, completeness or usefulness of any information, apparatus, product or process disclosed, or represents that its use would not infringe privately owned rights.

Printed in the United States of America. Available from

National Technical Information Service

U. S. Department of Commerce 5285 Port Royal Road

Springfield, Virginia 22151

Price: Printed Copy $\$ \ldots \ldots$; Microfiche $\$ 3.00$

*Pages

$$
1-50
$$

$51-150$

$151-325$

$326-500$

501-1000
NTIS

Selling Price

$\$ 4.00$

5.45

7.60

10.60

13.60 


\title{
IMPURITY MEASUREMENTS IN PLT
}

\author{
by \\ H. F. Dylla \\ Plasma Physics Laboratory, Princeton University \\ Princeton, New Jersey 08540
}

PPPL-1377

September 1977

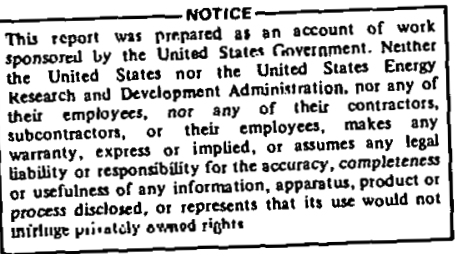




\title{
IMPURITY MEASUREMENTS IN PLT
}

\author{
H. F. DYLLA \\ Plasma Physics Laboratory, Princeton University \\ Princeton, New Jersey 08540
}

\begin{abstract}
During the first eighteen months of PLT operation, measurements on impurity-related effects have been obtained using Thomson scattering, visible, vacuum ultra-violet and soft $x$-ray spectroscopy, mass spectrometry, bolometry, and surface analysis. A brief review is presented of these diagnostic techniques and the present characterization of the discharge cleaning process and impurity related effects in high power discharges.
\end{abstract}

Prepared fior the ERDA report "Impurities in Tokamaks", T.S. Hsu, Editor 
Impurity Measurements in PLT

During the first 18 months of PLT operation, measurements on impurity-related effects have been obtained using Thomson scattering, visible, vacuum ultra-violet and soft $x$-ray spectroscopy, mass spectrometry, bolometry, and surface analysis. A listing of all diagnostics that are in use or planned for near-term impurity studies is given in Table I. A brief description is presented of the present characterization of the discharge cleaning process and the impurity-related effects. observed during high power discharges.

\section{Discharge Cleaning}

Two modes of discharge cleaning have been used to condition the PLT vacuum vessel. A comparison of the discharge parameters of the two mudes is given in Table 2. The first mode of discharge cleaning investigated was a standard hydrogen tokamak discharge run at lower discharge currents (20-100 kA), lower. magnetic fields $(1-10 \mathrm{kG})$, and higher repetition rates $\left(1 / 12-1 / 30 \mathrm{~s}^{-1}\right)$ than the typical high-power PLT discharge (> $\left.1 / 90 \mathrm{~s}^{-1}\right)$. Such conditions resulted in a discharge typically lasting 10-100 $\mathrm{ms}$ with a central electron temperature and density of $100 \mathrm{eV}$ and $10^{13} \mathrm{~cm}^{-3}$ respectively. After major vacuum openings, it was generally necessary to discharge clean in this mode for 5-10 days (approximately 104) discharges before relatively disruption-free high power discharges could be maintained for several hundred milliseconds. This mode of discharge 
cleaning was used on PLT from Dec. 1975 through Feb. 1977, and in general, it had the effect of reducing the carbon impurity level by an order of magnitude, but had little effect on the oxygen impurity level. ${ }^{1} z_{\text {eff }}$ values were not reduced below 5-6 for $\mathrm{H}_{2}$ discharges.

The second mode of discharge cleaning was similar to a mode described by R. Taylor. 2 A hydrogen discharge was run in a tokamak mode; however, the fill gas pressure was adjusted to yield a partially-ionized plasma with correspondingly low values of the plasma current $(2-4 \mathrm{kA})$, electron density $\left(1-5 \times 10^{11} \mathrm{~cm}^{-3}\right)$, and electron temperature $(2-5 \mathrm{eV})$. The low power in the resulting discharge $(20-30 \mathrm{~kW})$ enabled the repetition rate to be increased to $\cdot 5-2 \mathrm{~s}^{-1}$. The first extended application of this type of discharge cleaning in PLT occurred in early February 1977, which resulted in the production of bistable high-power discharges, i.e., discharges characterized by either peaked or hollow electron temperature profiles, depending on the details of the programmed gas injection. Generally, the oxygen impurity level was reduced by a factor of $3-5$ after $10^{4}$ low power discharges $^{3}$; and $z_{\text {eff }}$ was reduced ${ }^{4}$ to values in the range of $1.5-2.5$.

A major difference between the two modes of cleaning is seen in the residual gas spectra immediately following each discharge cleaning pulse. The standard cleaning discharges produce primarily $\mathrm{CH}_{4}\left(1-5 \times 10^{-7}\right.$ torr) and $\mathrm{CO}\left(1-10 \times 10^{-7}\right.$ torr). The time constant of the $\mathrm{CH}_{4}$ transient was longer than the scaled $\mathrm{H}_{2}$ pump-out time for the vacuum system; however, the 
Co transient disappeared rapidly (< $300 \mathrm{~ms}$ ), indicating nearly complete pumping of this gas by the wall. In contrast, the low temperature cleaning discharges produced primarily $\mathrm{H}_{2} \mathrm{O}$ $\left(1-2 \times 10^{-6}\right.$ torr) and $\mathrm{CH}_{4}\left(1-10 \times 10^{-7}\right.$ torr). The resulting $\mathrm{H}_{2} \mathrm{O}$ transient was equal to several pump out times enabling removal of some fraction of the volatile oxygen by the vacuum pumps rather than redeposition onto the wall. The time averaged $\mathrm{H}_{2} \mathrm{O}$ partial pressure produced during low-temperature discharge cleaning was observed to decrease with two time-constants. (See Fig. 1.) The first time constant is of the order of $10^{3}$ pulses and most likely is indicative of the removal of a looselybound oxygen adlayer (surface oxide, adsorbed $\mathrm{H}_{2} \mathrm{O}$, etc.); and the second time constant is of the order of $10^{4}-10^{5}$ pulses and possibly indicates the removal of more tightly bound oxygen from bulk oxide $\left(\mathrm{FeO}-\mathrm{Cr}_{2} \mathrm{O}_{3}\right)$ layers of the stainless steel.

Elemental surface analysis of hydrocarbon covered stainlesssteel samples exposed to both types of discharge cleaning showed approximately equal carbon removal rates after $10^{3}-10^{4}$ pulses. (See Fig. 2.) In the standard mode the rate of carbon removal was found to be inversely proportional to $\mathrm{B}_{\mathrm{T}^{\prime}}$, which suggests that the unconfined ions are important wall reactants. No significant $\mathrm{B}_{\mathrm{T}}$ dependence was found for the low temperature mode which is consistent with the assumption that such a discharge is unconfined and lacking any distinctive current channel. Clean indium thin films exposed to both discharge cleaning procedures showed no metal transport by the l.ow temperature mode, but 
occasional transport of both liner ( $\mathrm{Fe}, \mathrm{Cr}$ ) and limiter (W) metals by the standard mode.

The mechanisms responsible for the removal of adsorbed carbon and oxygen atoms during discharge cleaning have not been established. However, we infer that chemical processes involving bond-breaking by incident atomic hydrogen and subsequent (atomic and molecular) hydrogen attachment are important. Examples of possible reactions of atomic hydrogen with adsorbed hydrocarbons yielding $\mathrm{CH}_{4}$ have been given by $\mathrm{Rye}^{5}$. The most likely reactions yielding $\mathrm{H}_{2} \mathrm{O}$ based on equilibrium constants are empirically:

$$
\begin{gathered}
\mathrm{FeO}+2 \mathrm{H} \rightarrow \mathrm{Fe}+\mathrm{H}_{2} \mathrm{O} \uparrow \\
\mathrm{Cr}_{2} \mathrm{O}_{3}+6 \mathrm{H} \rightarrow 2 \mathrm{Cr}+3 \mathrm{H}_{2} \mathrm{O} \uparrow
\end{gathered}
$$

To summarize: both standard and low temperature discharge cleaning will decrease carbon impurity levels by producing $\mathrm{CH}_{4}$ which is subsequently easily removed by the vacuum system due to its low sticking. probability on the vacuum vessel walls. With regard to decreasing the oxygen impurity level, we find that low temperature discharges are required to produce a molecular product with a sufficientíy low sticking probability $\left(\mathrm{H}_{2} \mathrm{O}\right.$ as opposed to $\mathrm{O}, \mathrm{OH}$, or $\left.\mathrm{CO}\right)$ to enable removal of gaseous oxygen by the vacuum pumps.

High Power Discharges

Initial operation of PLT in the high power mode (Jan.Feb., 1976) was characterized by short (< $100 \mathrm{~ms}$ ) disruptive discharges with large $\left(\mathrm{n}_{I} / \mathrm{n}_{e}>20 \%\right)$ carbon and oxygen impurity levels. 
In later operation (March), stable discharges of $500 \mathrm{kA}$ were obtained for durations of one second ${ }^{6}$. During the quasi-steady state portion of these discharges, the influx rates of $\mathrm{H}, 0$, and $C$ were constant and approximately in the ratio 60:10:1 respectively (see Fig. 3). Since the electron density remained roughly constant, the plasma composition probably had the same relationship, implying $\bar{z} \simeq 5-6$ and a ratio of $n_{p} / n_{e}$ of $1 / 3-1 / 2$. No significant radiation from the liner materials ( $\mathrm{Fe}, \mathrm{Cr}, \mathrm{Ni}$ ) was observed during the initial (Jan.-Mar.) period. However, such radiation did appear after July 1976, but not at levels believed to significantly affect the discharge characteristics (see Fig. 4a). Measurements by VUV spectrometry ${ }^{7}$ and soft $x-r a y$ pulse-height analysis ${ }^{8}$ typically yielded Fe densities of $\sim 3 \times 10^{10} \mathrm{~cm}^{-3}$, and $\mathrm{Cr}$ and $\mathrm{Ni}$ densities of $\sim 1 \times 10^{10} \mathrm{~cm}^{-3}$. During the first year of operation, observations by X-ray PHA of emission lines attributed to $W$ (the limiter material) were limited to runaway discharges (Fig. 4h).

High power discharges obtained during the most recent operating period (Jan.-May 1977) were characteristically bistable with the electron temperature alternating between peaked or hollow profiles, depending on the details of the programmed gas feed and current rise (see Table 3). Radiation up to a level

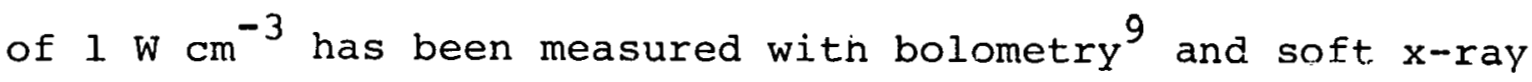
20-200 $\AA$ ) detectors $1,0,11$. The source of this radiation has been tentatively ascribed to tungsten (the limiter material). The

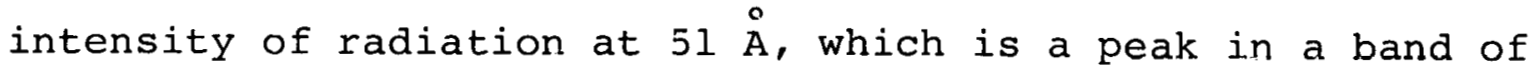
lines ascribed to $W x x-W x_{x x I V} 12,13$, is seen to decrease by an 
order of magnitude when a relatively small quantity $(\sim 1 \%$ of the fill pressure) of $\mathrm{Ne}$ is injected into a discharge during the steady-state portion $^{11}$ (see Fig. 5). Such a small quantity of Ne should not affect the plasma-wall or plasma-limiter chemistry during the course of one discharge, but is capable of significantly cooling the edge-plasma by line radiation. A cooler edge-plasma temperature would lower the limiter potential which would in turn: (1) decrease limiter sputtering by decreasing the energy of impacting impurity (primarily 0 ) ions on the limiter; or (2) would decrease the vaporization of limiter material by minimizing the probability of vacuum $\operatorname{arcs}^{14}$ occurring on the limiter surface. Either mechanism would be a source of $W$ in the discharge. Experiments are planned which will correlate spectroscopic measurements with limiter potential and edgetemperature measurements.

The most successful PLT discharges in terms of a high density-confinement time product and minimum impurity content have been produced in pure He (see Table 3). High density operation (> $10^{14} \mathrm{~cm}^{-3}$ ) has not yet been possible with pure $\mathrm{H}_{2}$ (or $\mathrm{D}_{2}$ ) discharges. A possible reason for the difference in performance is the edge-cooling which results from the higher radiation of $\mathrm{He}^{+}$ions. Other differences to be considered include the lack of chemical reactivity of $\mathrm{He}$ with the wall components and the smaller He charge-exchange probabilities. Surface analysis measurements have confirmed the presence of $W$ in the discharge and have shown that $W$, along with liner material, 
is transported around the torus by the high power discharges. Long-term changes in surface conditions have been monitored by the periodic removal of a variety of sample substrates (stainless steel, alumina, silicon) exposed to PLT discharges at the vacuum vessel wall, and subsequent analysis by Auger electron spectroscopy (AES) and photoelectron spectroscopy (ESCA). Samples were removed from a diagnostic port at the midplane of the torus $170^{\circ}$ from the limiter position after three separate exposure intervals. The preliminary results of the subsequent analyses are given in Table 4. The most striking difference between the three groups is the considerably larger quantity of metal (FC, $\mathrm{Cr}, \mathrm{Ni}$, and W) deposiled un the salules exposed after Jan: 1977, particularly group B, which was exposed during the first application of the low temperature discharge cleaning (Jan.-Mar. 1977). Examination of the deposited metal films by high resolution ESCA indicated nearly complete oxidation of the $\mathrm{Fe}$, and no evidence of reduction of the nascent $\mathrm{Al}_{2} \mathrm{O}_{3}$ or $\mathrm{SiO}_{2}$ oxlde layers on the alumina and silicon samples.

Short-term changes in surface conditions and time-resolved measurements of impurity out-fluxes have been obtained with the Surface Analysis Station (SAS) diagnostic ${ }^{15,16}$. The SAS is capable of exposing a well-characterized metal film (for example, In, $A 1$, or stainless steel) to a given number of discharges at a variable distance behind the limiter radius. Additionally, the sample film can be rotated past an exposure aperture during the course of a series of discharges to record time-resolved 
surface changes. In general, when the SAS probe was exposed 2-10 $\mathrm{cm}$ outside the limiter radius, only low $\mathrm{z}$ impurities $(0, \mathrm{C}, \mathrm{Cl})$ were easily detected. Fig. 6 shows the time-resolved deposition onto the probe when it was positioned $4 \mathrm{~cm}$ behind the limiter. Note, in particular, the decreased oxygen outflux which was obtained immediately after low temperature discharge cleaning. With the SAS probe located $1 \mathrm{~cm}$ behing the limiter radius, Fe and occasionally $\mathrm{W}$ were detected. Fe deposition onto the SAS probe, when exposed at the midplane nearly parallel $\left(8^{\circ}\right)$ to the toroidal magnetic field, was measured at a rate of $1.5 \times 10^{13} \mathrm{~cm}^{2} \mathrm{~s}^{-1}$ with the outflux observable $50 \mathrm{~ms}$ after the initiation of the discharge, growing to a plateau as the current reaches a plateau and decaying as the current decays (see Fig. 7). W deposition was usually below a sensitivity limit of $4 \times 10^{12} \mathrm{~cm}^{2} \mathrm{~s}^{-1}$. With the sAS probe exposed at an angle of $20^{\circ}$ (i.e., with an increased solid angle for interception of ion orbits) the deposition rates of both $\mathrm{Fe}$ and $\mathrm{W}$ were observed to increase an order of magnitude. 
We have identified two regimes of interaction of the SAS probe with the plasma: (1) With the probe positioned behind the limiter scrape-off $(2-10 \mathrm{~cm})$, and parallel (or nearly parallel) to the toroidal field, the probe is sampling primarily neutral particles (i.e., charge exchange neutrals during the developed segment of the discharge and recombination neutrals at the termination of the discharge. (2) With the probe positioned closer to the limiter scrape-off, or with an increased angle of interception of the toroidal field lines, the probe samples the the ion flux in the edge plasma.

The time behavior of the observen 1nw-7, nutflux (ब.g., Fig. 6) is similar to the time profile of the VUV emission from the partially ionized atoms within the body of the plasma and is understandable in terms of the same atomic processes. Generally, we observe the Low-L outflux peaking at the beginning and end of the discharge. With the initial ionization a variety of chemical and charge-exchange reactions are probable, and ion confinement is also ponr. With the achievement of steady state conditions in the discharge, the burnout of the low-Z impurities and increased confinement of the discharge decreases the outflux. Finally, with the termination of the discharge, recombination will increase the outflux.

with regard to high-z impurities, insufficient data has been collected to generally characterize their behavior. However, we draw one important conclusion based on the continual buildup of metallic layers observed on recessed areas of the PLT vacuum vessel (see Table 4), combined with the observation of the time behavior of the Fe outflux (Fig. 7), which shows that the Fe outflux peaks 
early (within $50 \mathrm{~ms}$ ) and continues during the developed segment of the discharge. We conclude that local equilibrium between exosion (by sputtering) and deposition does not occur. There are sources and sinks for the metal impurities. We thus conclude that sputtering of $\mathrm{Fe}$ (and possibly $W$ ) from the vacuum vessel walls is not responsible for the $\mathrm{Fe}(W)$ contamination in the plasma. More detailed studies are necessary to identify the source and mechanism of introduction of Fe into PLT ohmically-heated discharges. Although the present levels of $\mathrm{Fe}$ in the discharge do not seem to have any detrimental effects, this situation may change as high power neutral beam heating experiments increase both the ion temperature and the wall-loading. The more serious high-z problem is the contamination of the discharge with the limiter material, $W$. The Ne injection experiments (Fig. 5) indicate that $W$ is entering the discharge directly from the limiter, rather than from the $W$-containing metallic film on the vacuum vessel wall. We have identified two likely mechanisms for the introduction of $W$ into the discharge, both related to the edge temperature within the limiter scrape-off region: (1) oxygen ion sputtering of the limiter, and (2) vacuum arcs on the limiter surface.

Future experiments related to the $\mathrm{W}$ problem include: (1) a further examination of the coupling between the low-z (0) impurities and $W$ transport through the continued application of low temperature discharge cleaning; (2) gas injection experiments with the purpose of modifying the edge-temperature profile; and (3) tests of graphite as a replacement limiter material. 


\section{ACKNOWLEDGEMENTS}

The author acknowledges the contributions of the PLT Experimental Group in the compilation of this report, especially

K. Bol, N. Bretz, S. Cohen, D. Eames, R. Hawryluk, E. Hinnov, J. Hosea, H. Hsuan, D. Johnson, E. Meservey, N. Sauthoff, W. Stodiek, S. Suckewer, and S. von Goeler.

This work was supported by the U. S. Energy Research and Development Administration Contract EY-76-C-02-3073. 
REFERENCES

[ 1] DYLLA, H. F., COHEN, S. A., and HINNOV, E., Bull. Am. Phys. Soc. Ser. II, 21, (1976) 1160 .

[ 2] OREN, L., and TAYLOR, R. J., UCLA Rep. PPG-2.94 (March 1977).

[ 3] SUCKEWER, S., Private Communication.

[ 4] BRETZ, N., JOHNSON, D., Private Communication.

[ 5] RYE, R. R., Chemical Institute of Canada, American Chemical Society, (American Chemical Societ:y, Montreal, 1977) 2nd Joint Conference, Montrea 1, (1977) paper COLL 29.

[ 6] GROVE, D., et al., in Plasma Physics and controlled Nuclear Fusion Research (International Atomic Energy Agency, Vienna, 1977)Vol. I, 21.

[ 7] HINNOV, E., JOHNSON, D., MESERVEY, E., and VON GOELER, S., Bull. Am. Phys. Soc. 21 (1976) 1159.

[ 8] VON GOELER, S. , EAMES, D., GREENBERGER, A., RONEY, W. , SAUTHOFF, N., STODIEK, W., Bull. Am. Phys. SOc. 21 (1976) 1160 .

[ 9] HSUAN, H., Private Communication.

[10] VON GOELER, S., SAUTHOFF, N., Private Communication.

[11] HINNOV, E., Private Communication.

[12] ISLER, R. C., NEIDIGH, R. V., and COWAN, R. D., Phys: Rev. Letters (to be published).

[13] HINNOV, E., MATTIOLI, M. , Ultra Violet and X-ray Spectroscopy of Astrophysics and Laboratory Plasmas 5th Colloquium, London (1977).

[14] MC CRACKEN, G. M., Chemical Institute of Canada, American Chemical society, (American Chemical Society, Montreal, 1977) 2nd Joint Conference, Montreal, (1977) paper COLL. 37 .

[15] DYLLA, H. F., and COHEN, S. A., Nucl. Matter. 63 (1976) 487 .

[16] DYLLA, H. F., and COHEN, S. A., J. Vac. Sci. Technol. 14 (1977) 565 . 
TABLE I

IMPURITY RELATED DIAGNOSTICS IN USED OR PLANNED FOR PLT

Diagnostic Schedule Comments

I. Photon Spectroscopy
1. Visible
Operational
3 Jarrell Ash 1/2 M Monochrometers.
Line scan across major diameter only.
Measure $\mathrm{H}_{2}$, He, and impurity influxes.
2. Near UV
spectroneter
Operational
Scannable across plasma edge; mexsure 'l' $i$ by Doppler broadening.
3. Grazing
Incidence
Operational
Scannable from $0-25 \mathrm{~cm}$; measure
UV Bichromomator
impurity densities and influx rates.
4. 3ofl X-kày
Pulse Height
Analyzer.
Operaliunal scannable from 0 - 40 rim; mésure $\mathrm{T}_{\mathrm{e}}$ and impurity concentration.
5. Curved-crystal
Spectrometer
Operational
Measure ionization status of high $\mathrm{Z}$ ions in plasma core.
$G$ : Vera Goft
$\mathrm{X}$-Ray
Detector
Operational
Measure spatlal distribuelon of low
energy $x$-rays
7. Bolometers
Operational
Measure spatial distrihution of energr vutilux by sdalatlon and charge exchange.

II. Particle Spectroscopy
1. Diagnostic
$9 / 01 / 77$
Neutral Beam
Measuire $z_{\text {eff }}$ and $q$ profiles
2. Residual Gas
Analyzex
Operational
Measure partial pressures of all gas during and after discharges.
3. Surface
Analysis
Station
Uperational
Measure density and outflux of impuritics in the scrape-off region. 
Diagnostic Schedule Comments

III. Miscellaneous Diagnostics

1. Langmuir Probes

M

2. Surface Analysis station

3. Electron Stimulated Desorption Probes

4. Ti Gettering Probes

5. Impurity Injection
Operational

Measure $\mathrm{n}_{e}$ and $\mathrm{T}_{\mathrm{e}}$ in the scrape-off region.

Operational Determine composition of surfaces facing the plasma.

Operational Measure amount of loosely-bound gases on tokamak wall.

Reduce contamination in plasma.

$7 / 01 / 77$

- Operational

- $6 / 78$

- $7 / 01 / 77$
Inject high $\mathrm{Z}$ gases with pulse-values Inject metal atoms with laser evaporation Inject carbon pellets with electrostatic acceleration. 
TABLE 2

COMPARISON OF DISCHARGE CLEANING PARAMETERS

\begin{tabular}{|c|c|c|}
\hline & $\begin{array}{l}\text { Standard } \\
\text { Method } \\
\end{array}$ & $\begin{array}{c}\text { New } \\
\text { Method } \\
\end{array}$ \\
\hline Discharge Duration (s) & .04 & .04 \\
\hline Repetition Rate $\left(\mathrm{s}^{-1}\right)$ & $1 / 30$ & $1 / 2$ \\
\hline Magnetic Field (kG) & 2 & 2 \\
\hline Plasma Current (KA) & 100 & 2 \\
\hline Loop Voltage (V) & 3 & $1: 2$ \\
\hline Peak Power $(\mathrm{kW})$ & $300 \mathrm{~kW}$ & $24 \mathrm{~kW}$ \\
\hline Peak Power Density $\left(\mathrm{w} / \mathrm{cm}^{2}\right)$ & .6 & .05 \\
\hline Average Power (w) & 400 & 500 \\
\hline Central Electron Density $\left(\mathrm{cm}^{-3}\right)$ & $2 \times 10^{13}$ & $2 \times 10^{11}$ \\
\hline Central Neutral Gas Density $\left(\mathrm{cm}^{-3}\right)$ & $10^{10}$ & $10^{13}$ \\
\hline Central Electron Temperature (ev) & 100 & $2-5$ \\
\hline Gases Produi:ed after a Discharge & $\mathrm{CH}_{4}, \mathrm{CO}$ & $\mathrm{H}_{2} \mathrm{O}, \mathrm{CH}_{4}$ \\
\hline$z_{\text {eff }}$ & $5-10$ & $1.5-2.0$ \\
\hline
\end{tabular}


TABLE 3

\section{DISCHARGE PARAMETERS}

$\begin{array}{ccccc}1 & 2 & 3 & 4 & 5 \\ \mathrm{D}_{2} & \mathrm{D}_{2} & \mathrm{D}_{2} & \mathrm{D}_{2}(\mathrm{Ne}) & \mathrm{He}\end{array}$

$I_{p}(\mathrm{ma})$

$t(s)$

$\overline{\mathrm{n}}_{\mathrm{e}}\left(10^{14} \mathrm{~cm}^{-3}\right)$

$n_{\text {eo }}\left(10^{14} \mathrm{~cm}^{-3}\right)$

$t_{\text {eo }}(\mathrm{keV})$

$t_{10}(\mathrm{keV})$

$\tau_{\mathrm{E}_{\mathrm{e}}}(\mathrm{ms})$

$\bar{z}$
.45

.45

.21

.25

.7

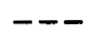

5.0

$2.0-3 \cdot 0$
.45

.45

.32

.50

1.5

$1 \cdot 0$

15.0

16.0

4.0

$8.0-12.0$

1.2
.50

.75

.9

1.3

.3

$2.0-3.0$

1.4

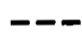

$12.0-16.0$

$50.0-60.0$

$2.0-3.0$

1. Hollow $\mathrm{T}_{\mathrm{e}}$ Profile

2. Peaked Te Profile with Increased Gas Injection

3. Air Leak $Q_{\mathrm{O}_{2}} \simeq 2 \cdot 10^{-5} \mathrm{t}-1 / \mathrm{s}$

4. $\mathrm{D}_{2}$ Discharge with $\sim 1 \%$ Ne Gas Injection

5. He Discharge with He Gas Injection 
TABLE 4

LONG-TERM INTEGRATED SURF'ACE MEASUREMENTS

Samples $\mathrm{A}^{\dagger}$

Exposure Time

Discharges

Coverage

(¿100 $\AA$ )

Samples B

Exposure Time

Discharges

Coverago*

( $900 \AA$ )
July - December 1976

High $\mathrm{T}_{e}, \mathrm{~N}_{e} \mathrm{PDC}$

High Power $\mathrm{H}_{2}, \mathrm{D}_{2}$, He

$20 \mathrm{ml} \mathrm{Fe}$

$1 ? \mathrm{mI} \mathrm{W}$

$30 \mathrm{ml} \mathrm{C}, \mathrm{O}$

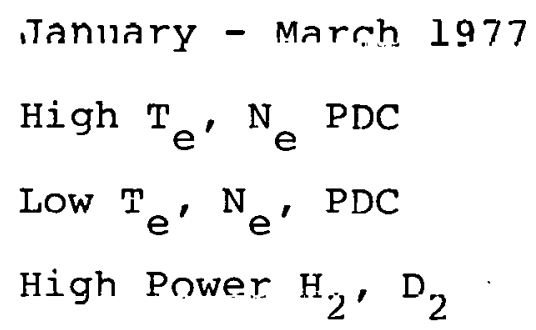

High $\mathrm{T}_{e}, \mathrm{~N}_{e}$ PDC

Low ' $e^{\prime} \mathrm{N}_{e}, \mathrm{PDC}$

High Power $\mathrm{H}_{2}, \mathrm{D}_{2}$

$\mathrm{Fe}$

Cr

W

$r$

0

Samples C

Exposiure Time

April - May 1977

Discharges

Low $\mathrm{T}_{e}, \mathrm{~N}_{e} \mathrm{PDC}$

High Power $\mathrm{H}_{2}, \mathrm{D}_{2}$, He, $\mathrm{Ne}, \mathrm{CH}_{4}$

Coveraqe*

( $200 \AA$ )

Fe
Cr
$\dot{W}$
C

t Measurements courtesy of Kaminsky, Gruen, and Lam of Argonne National Laboratory.

* Sputtering rate calibrated against the known sputtering rate of $5 \mathrm{keV}$ At on $\mathrm{TaO}$. 


\section{Figure Captions}

Fig. 1. Equilibrium partial pressure of $\mathrm{H}_{2} \mathrm{O}$ in PLT during rapid pulse (.5 pps), low temperature discharge cleaning. After 6000 discharge cleaning pulses .88 torr-liters of $\mathrm{O}_{2}$ was injected into the torus to quantify the observed $\mathrm{H}_{2} \mathrm{O}$ pressure drop with oxygen coverage. The initial rapid drop in $\mathrm{H}_{2} \mathrm{O}$ pressure is seen to correspond in order of magnitude to a coverage of one monolayer. Note that not all the injected $\mathrm{O}_{2}$ was removed by subsequent discharge cleaning.

Fig. 2. Observed changes in elemental surface composition of a hydrocarbon covered 304 stainless steel substrate exposed to a series of low temperature $\mathrm{H}_{2}$ discharge cleaning pulses at a repetition rate of .5 pps.

Fig. 3. Comparison of hydrogen and oxygen light intensities (proportional to influx rates) and average ele:ctron density, $\bar{n}_{e}$, before (dashed curves) and after (solid curves) discharge cleaning wall conditioning. Note that in spite of rapid increase of influx rate in the dashed-curve case, $\bar{n}$ does not rise. The discharge depicted by solid curves continued with little further change for another $800 \mathrm{msec}$. (PPPL 766060).

Fig. 4. (a) Soft $x$-ray spectrum of typical discharge following the (July) discharge cleaning perlod showing $\mathrm{Fe}, \mathrm{Cr}$, and $\mathrm{Ni} \mathrm{K} \alpha$ emission lines.

(b) Soft $x$-ray spectrum of runaway discharge which shows tungsten $\mathrm{L}$-lines in addition to the ( $\mathrm{Fe}, \mathrm{Cr}, \mathrm{Ni}) \mathrm{K} \alpha$ lines.

Fig. 5. Intensity of a Ne VIII VUV line and a soft-x-ray band $(51 \AA)$ attributed to $W$ during a high power $\mathrm{I}_{2}$ discharge in which $\sim 1 \% \mathrm{Ne}$ is injected after steady-state conditions had been reached. 
Fig. 6. Time-resolved measurements of the low-z impurity outflux from a series of high power PLT discharges. The upper graph shows the averaged outflux of 37 $\mathrm{H}_{2}$ discharges immediately after 8 hours of low temperature discharge cleaning. The lower graph shows the averaged outflux of $65 \mathrm{D}_{2}$ discharges (seeded with a small fraction of $\mathrm{Ne}$ ) which were not preceded by any discharge cleaning. The measurements were made by repeatedly exposing the same areas of a clean indium sample to the same portions of the .4's long discharges.

Fiq. 7. The lower graph shows the time-resolved Fe and $c$ outflux from $20 \mathrm{high}$ power discharges in $\mathrm{CH}_{4}$ (using a clean Al sample for the substrate). The impurity outflux can be compared with other diagnostic measurements characterizing the dischargc which are plotted with the same time scale. 


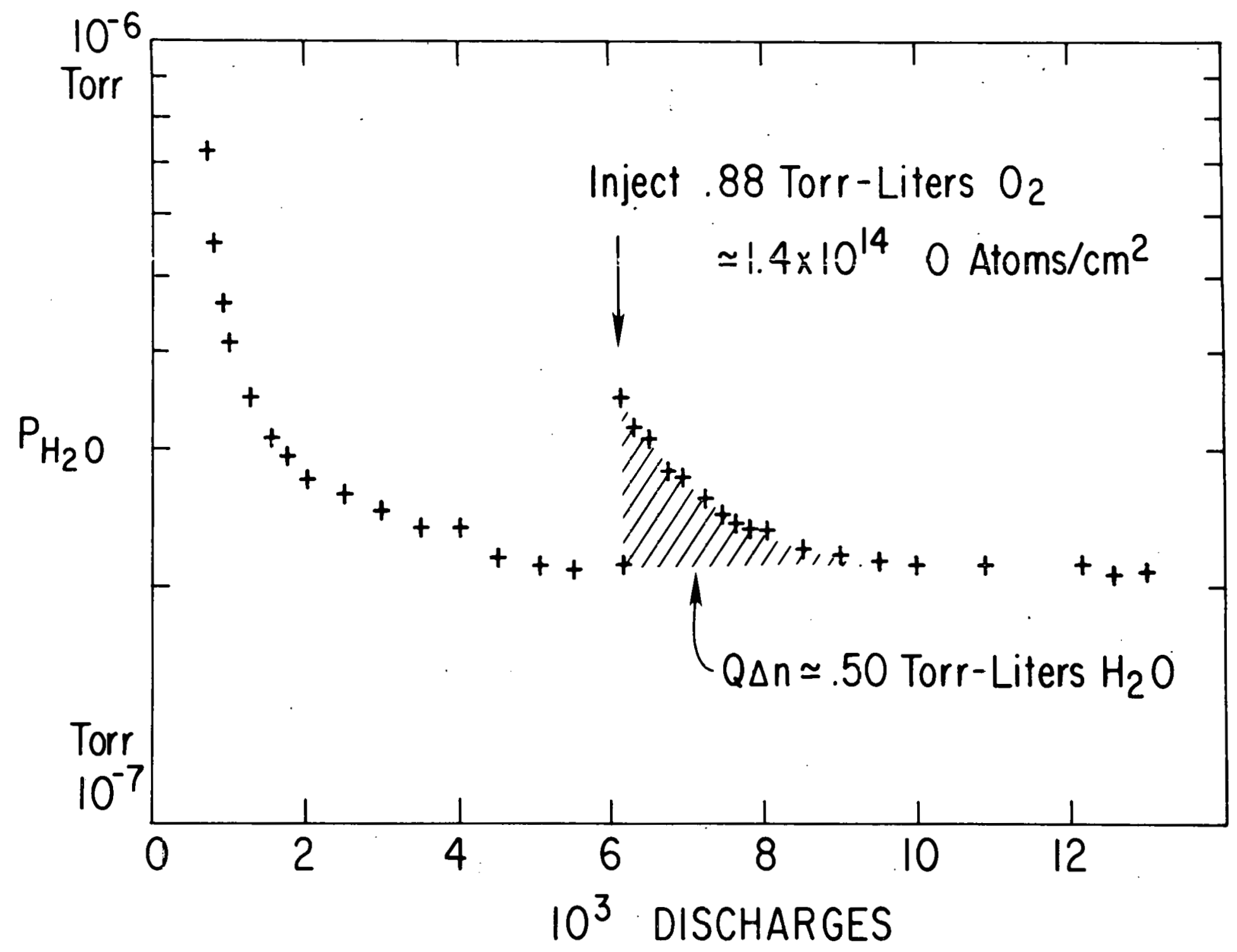




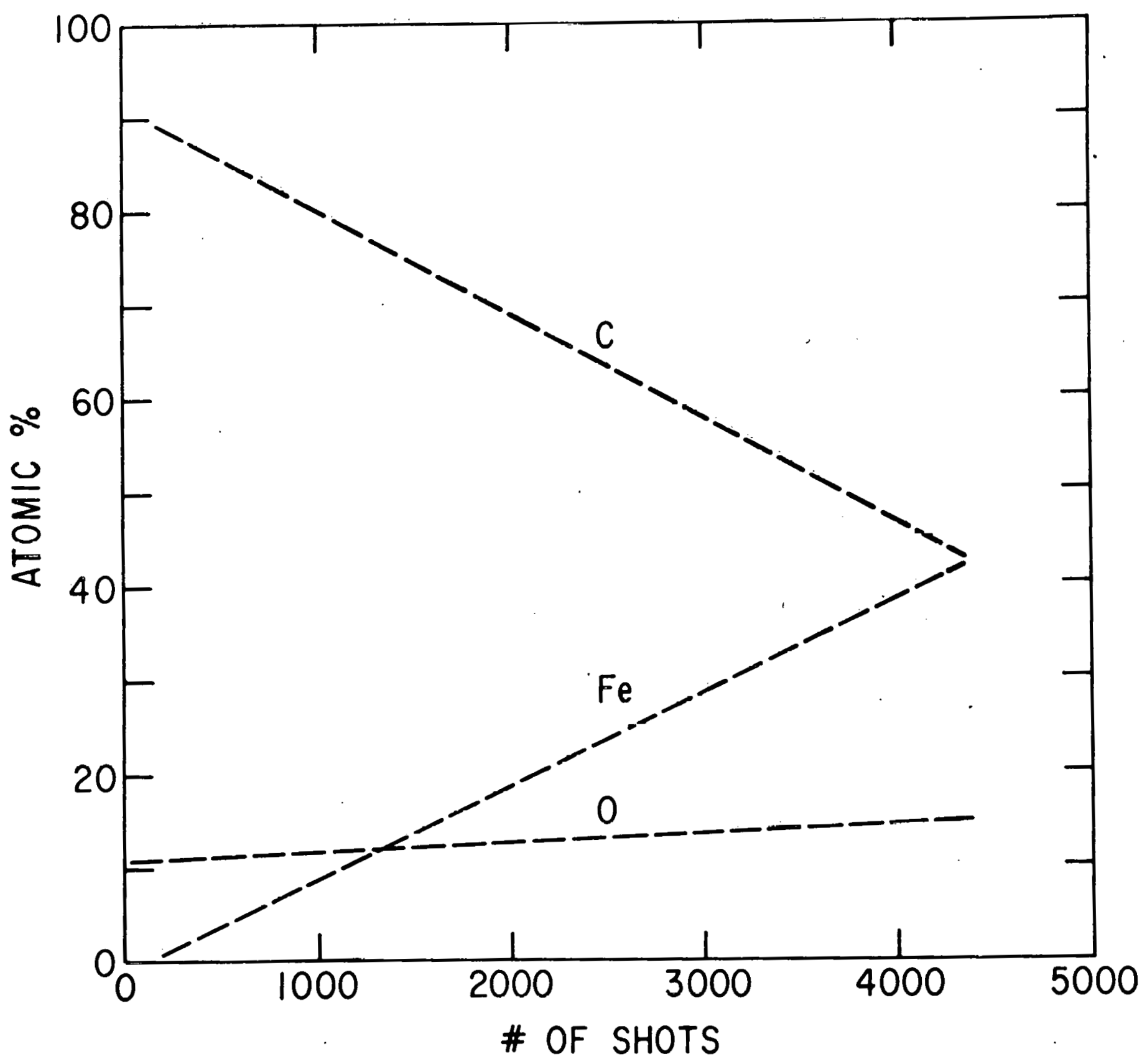

Fig. 2. 773387 


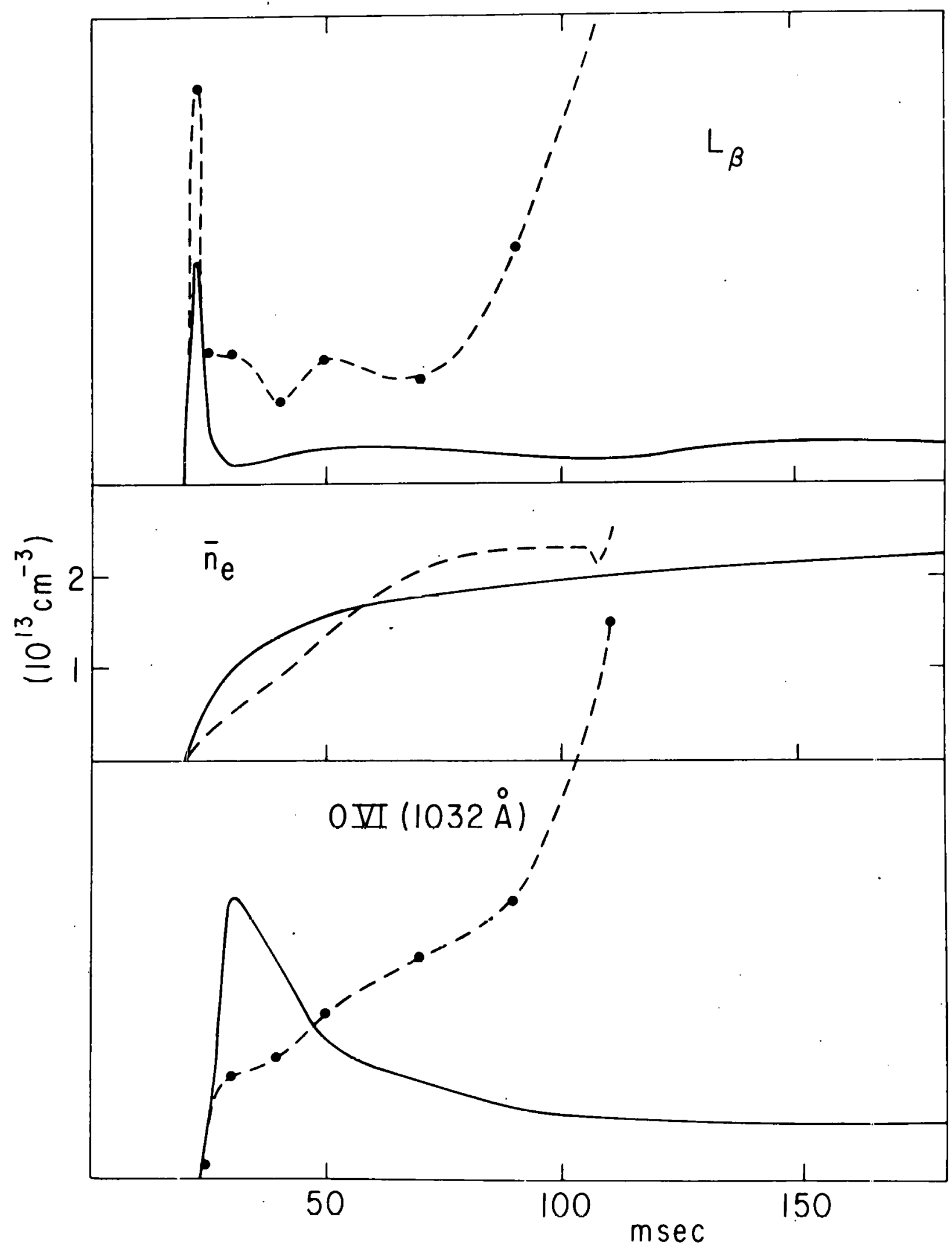

Fig. 3. 766060 
Shot \# 60690

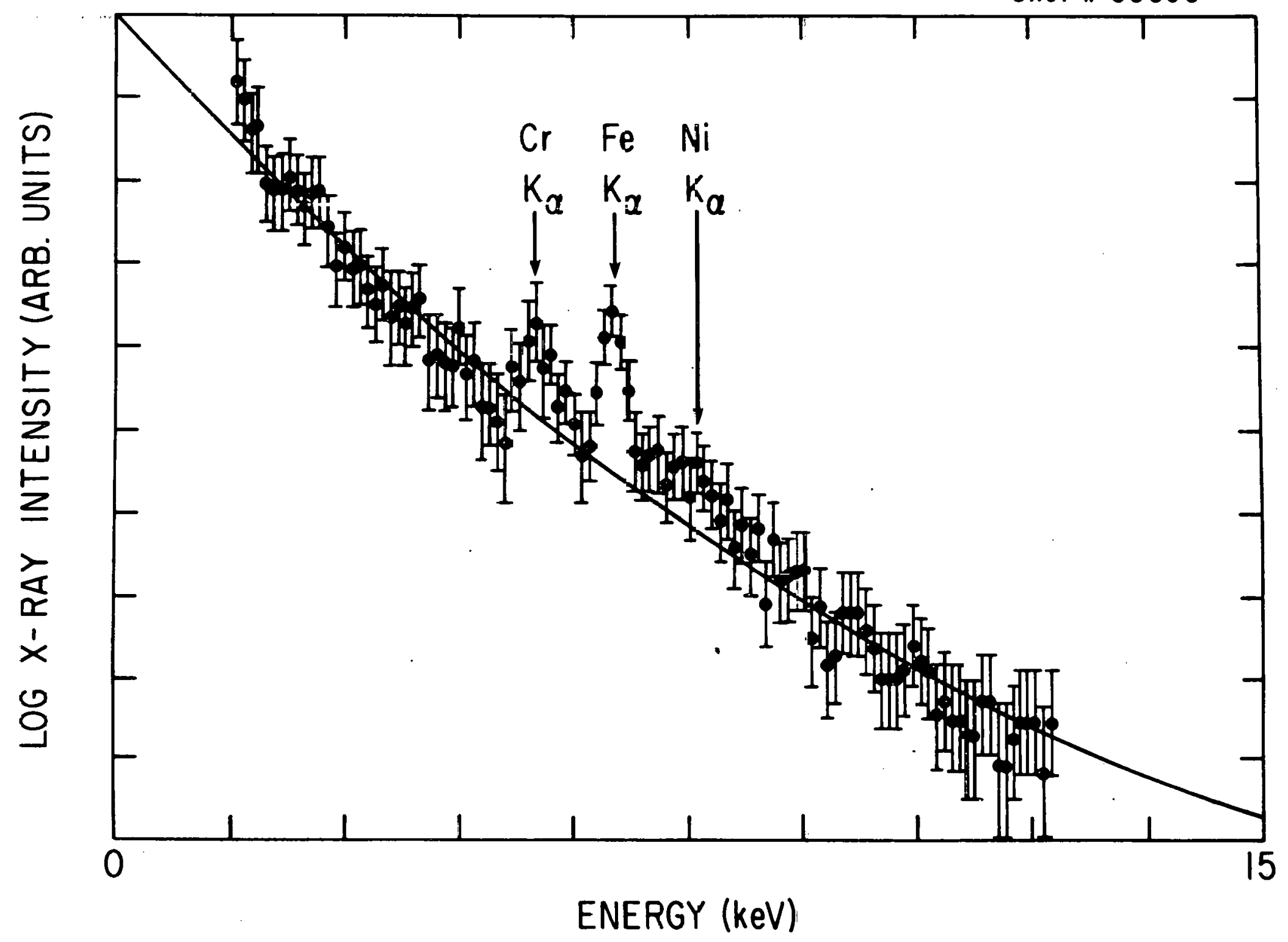




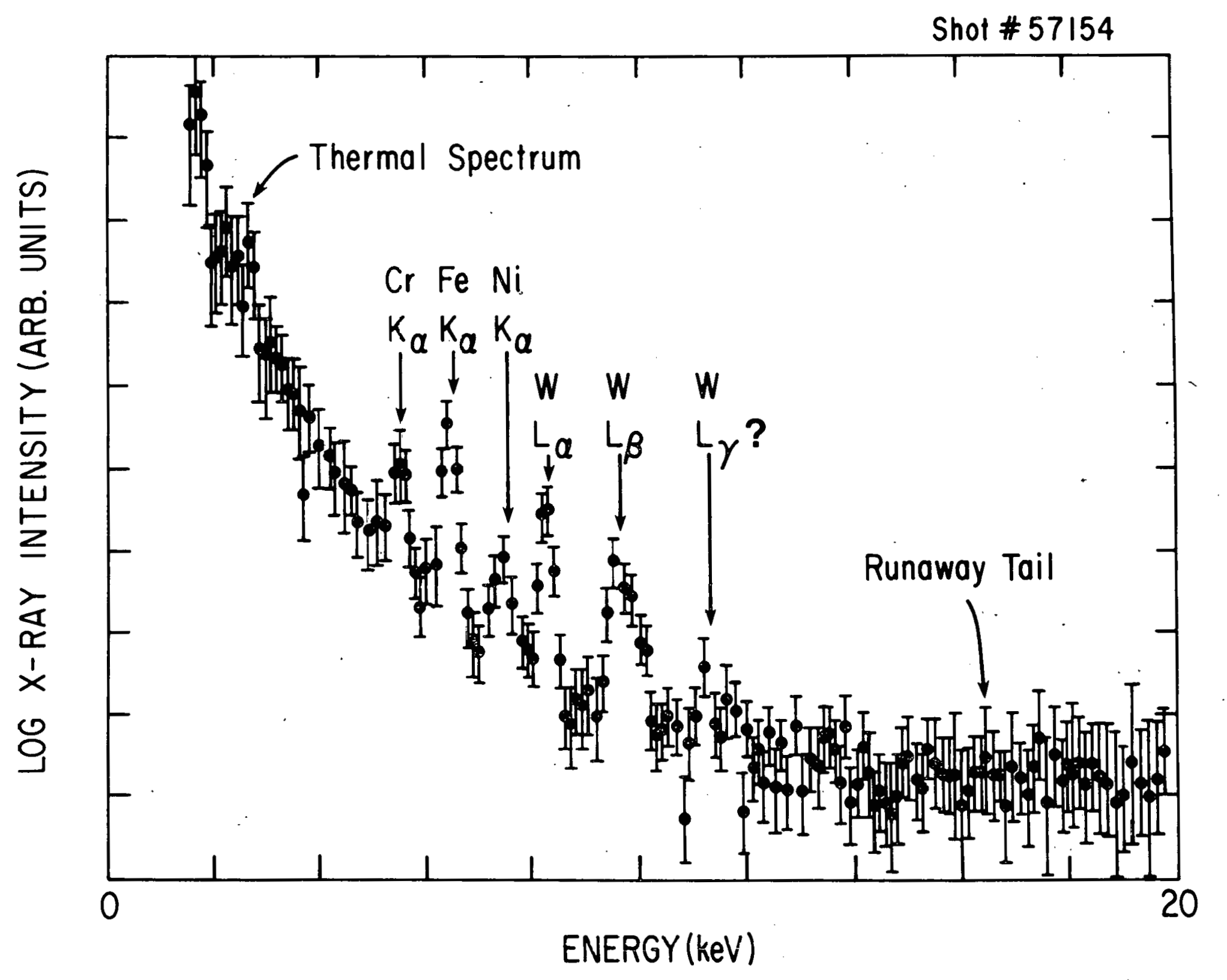




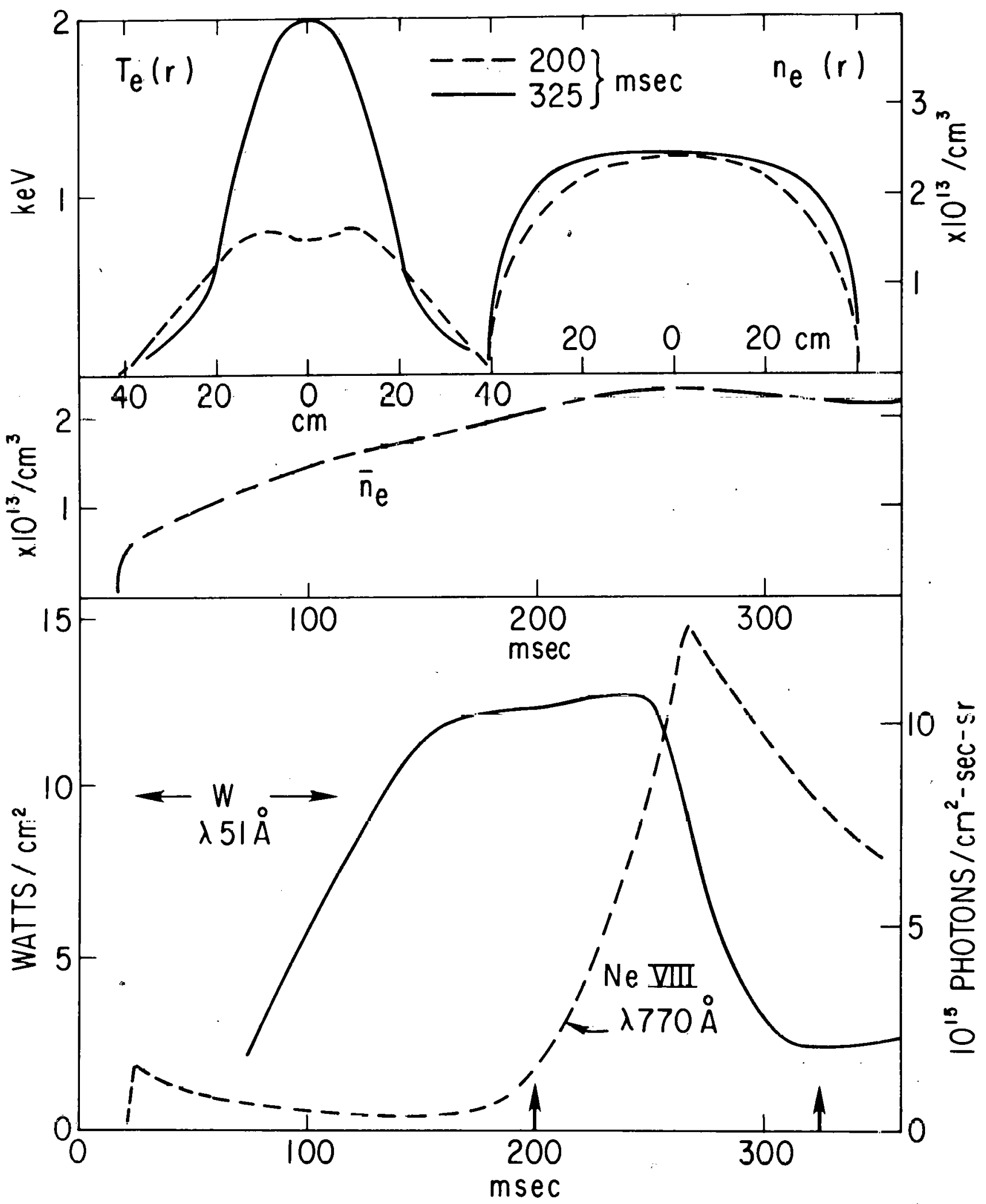

Fig. 5. 773675 


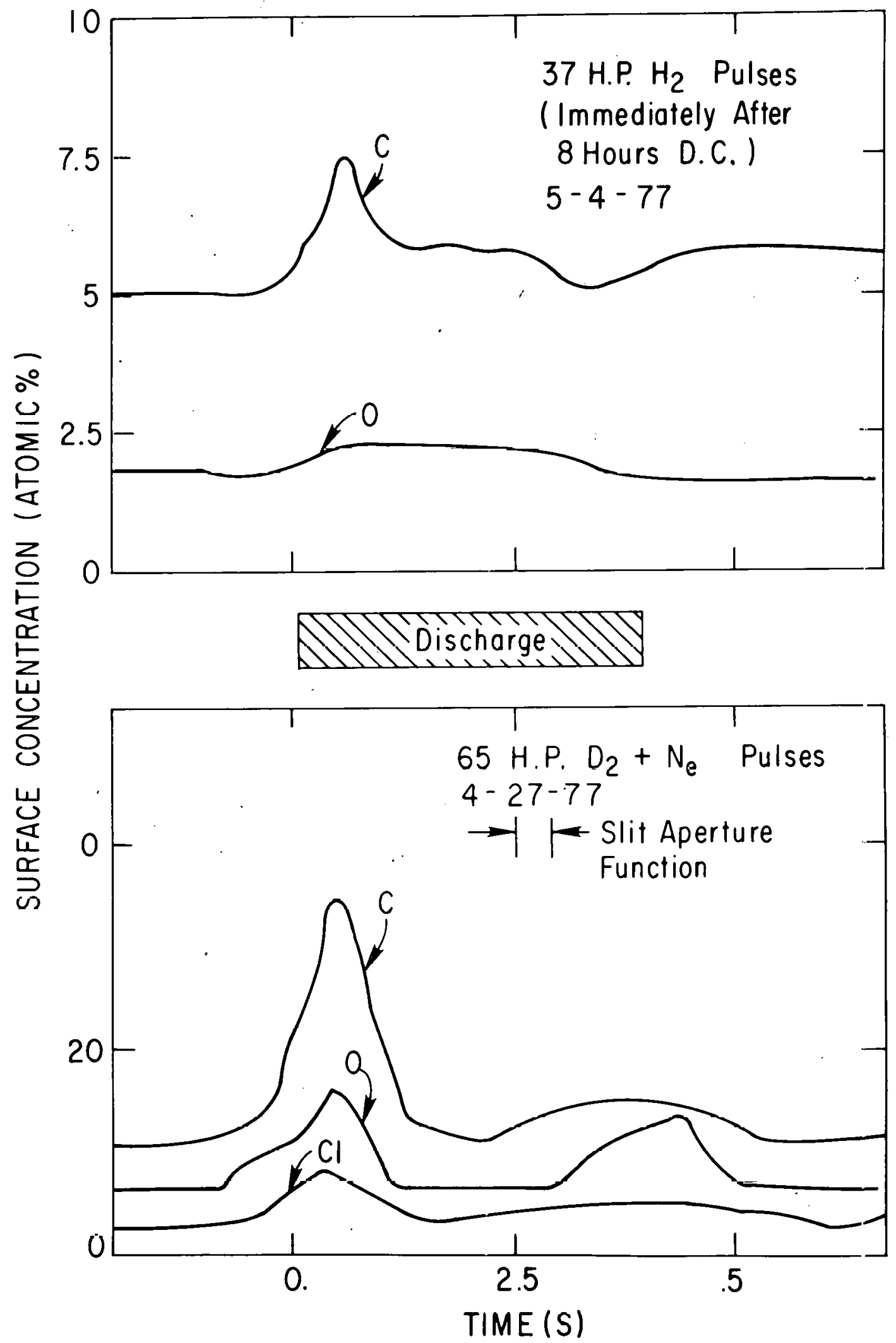

Fig. 6. 773395 


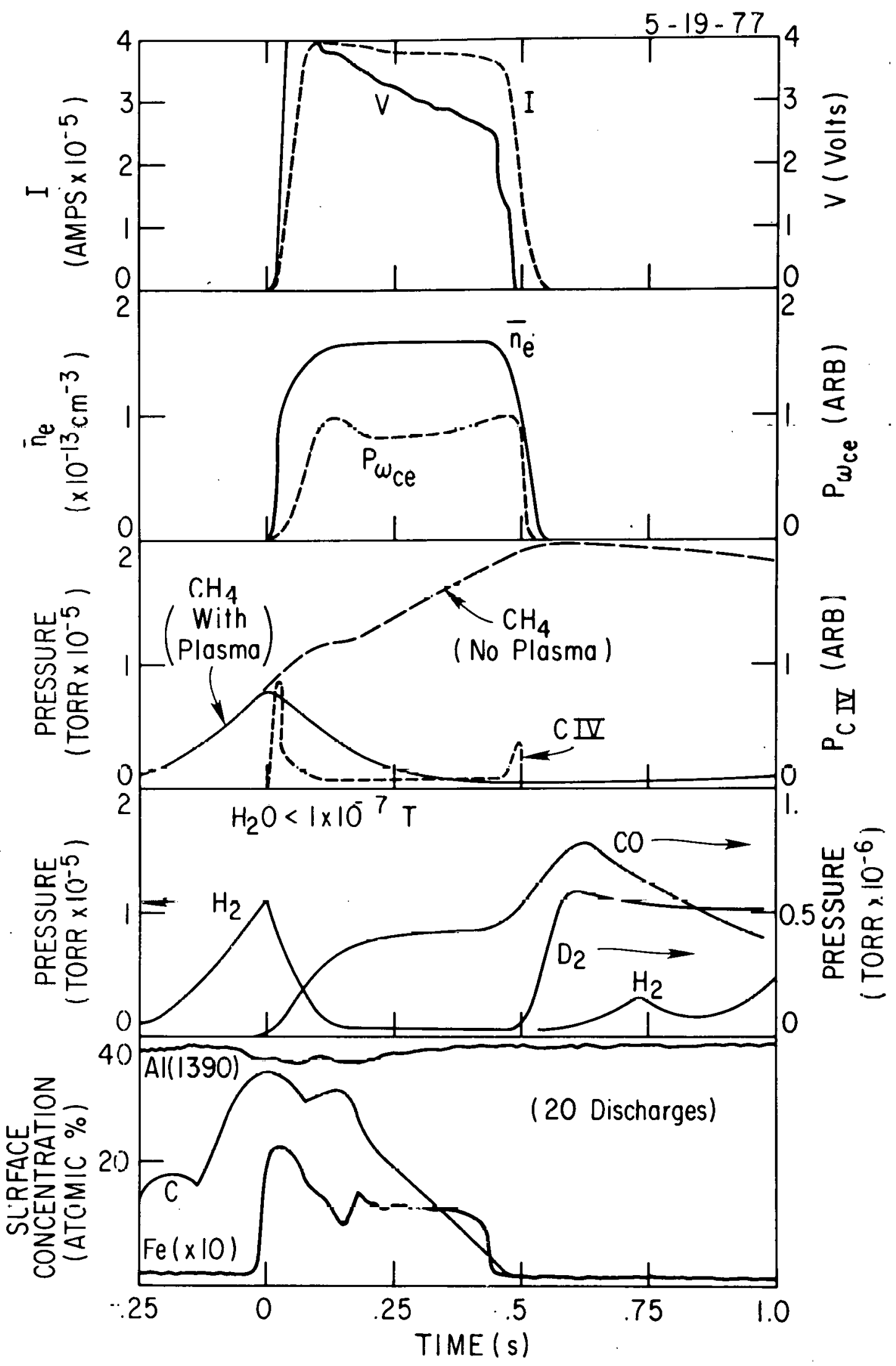

Fig. 7. 773405 